\title{
PON1 polymorphism, diabetes mellitus, obesity, and risk of myocardial infarction: Modifying effect of diabetes mellitus and obesity on the association between PON1 polymorphism and myocardial infarction
}

Jianping Li, MD, PhD ${ }^{1,3}$, Xiaobin Wang, MD, ScD ${ }^{2}$, Yong Huo ${ }^{3}$, Tianhua Niu, ScD ${ }^{1}$, Changzhong Chen, $M D^{1}$, Guoying Zhu, MD ${ }^{3}$, Yinmin Huang, $P h D^{4}$, Dafang Chen, $M D^{4}$, and Xiping $X u, M D, P h D^{1,4}$

\begin{abstract}
Purpose: Previous studies on PON1 gene polymorphism and the risk of coronary atherosclerotic diseases have been inconsistent. This may be in part due to population difference in prevalence of high oxidative stress and its modifying effect on the association. Diabetes and obesity are two major risk factors of myocardial infarction (MI) and associated with high oxidative stress. We investigated the association between PON1 Q192R polymorphism and the risk of myocardial infarction (MI) and in particular, whether the association can be modified by diabetes mellitus (DM) and obesity. Methods: We conducted a case-control study, including $154 \mathrm{Ml}$ cases and 154 controls enrolled in Beijing, China. Epidemiological and clinical data and PON1 Q192R genotype were obtained from each subject. Results: Without considering the modifying effect of DM and obesity, PON1 Q192R polymorphism was not associated with MI. When simultaneously examining the joint association of this polymorphism, DM, and obesity with $\mathrm{MI}$, as compared to subjects with QQ genotypes and without DM and obesity, subjects with QR/RR genotypes and with either DM or obesity had significantly higher risk of $\mathrm{MI}(\mathrm{OR}=3.6,95 \% \mathrm{Cl}: 1.5-8.7)$. Conclusion: Our data suggest that PON1 Q192R polymorphism was not independently associated with MI but further increased the risk of $\mathrm{Ml}$ among the subjects with DM, obesity, or both, the conditions associated with high oxidative stress. Genet
\end{abstract} Med 2005:7(1):58-63.

Key Words: human paraoxonase 1 gene (PON1), polymorphism, myocardial infarction, diabetes mellitus, obesity.

Coronary atherosclerotic disease (CAD), including its most severe form, myocardial infarction (MI), is the leading cause of death in many countries and is estimated to be the single largest cause of disease burden globally by the year $2020 .{ }^{1}$ Historically, CAD is much less common in China than in Europe and the USA. However, in recent years the prevalence of CAD in China has been on the rise, especially in the major cities. ${ }^{2}$ This upward trend may be in part due to a shift from traditional Chinese diet to a Westernized diet and decreased physical activity. In addition to environmental risk factors, there is growing evidence that genetic factors play an important role in predisposition to

\footnotetext{
From the ${ }^{1}$ Program for Population Genetics, Harvard School of Public Health, Boston, Massachusetts; ${ }^{2}$ The Mary Ann J. Milburn Smith Child Health Research Program, Children's Memorial Hospital and Children's Memorial Research Center, Boston Massachusetts; ${ }^{3}$ Department of Cardiology, Peking University the First Affiliated Hospital, Beijing, China; and ${ }^{4}$ Center for Eco-Genetics and Reproductive Health, Department of Genetics and Cell Biology, Peking University Health Science Center, Beijing, China.

Xiping Xu, MD, PhD, Program for Population Genetics, Harvard School of Public Health, Boston, MA 02115.

Received: June 9, 2004.

Accepted: September 27, 2004
}

DOI: 10.1097/01.GIM.0000151152.78092.CA
CAD. ${ }^{3}$ As lipoprotein oxidation is a key initial factor for atherosclerosis, genes involved in this process are good candidate genes for CAD. This study focused on human serum paraoxonase 1 (PON1) gene, encoding a HDL associated enzyme that hydrolyzes paraoxon and prevents low-density lipoprotein (LDL) oxidation. ${ }^{4,5}$

A number of studies have investigated the PON1 Q192R polymorphism in relation to the risk of CAD. A recent metaanalysis of 43 studies showed a weak overall association between the PON1 Q192R polymorphism and CAD. However, the results of these studies have been inconsistent across populations. $^{7-15}$ The $\mathrm{R}$ allele is associated with CAD in US Caucasians, ${ }^{7}$ in Asian Indians, ${ }^{8,9}$ and in Japanese, ${ }^{10}$ but not in French, ${ }^{11}$ Italians, ${ }^{12}$ Finns, ${ }^{13}$ Koreans, ${ }^{14}$ and in Chinese living in Singapore ${ }^{8}$ and Taiwan. ${ }^{15}$ The reasons for the inconsistent findings may be multiple, including small sample size, multiple comparisons, population stratification, and inadequate consideration of confounders and gene-environmental interactions. ${ }^{16}$ Another possibility is the study population difference in the prevalence of high oxidative stress, for example, diabetes mellitus (DM) and obesity. DM and obesity are two components of metabolic syndrome and major risk factors of CAD. It 
has been shown that lipid peroxide concentrations are significantly higher in metabolic syndrome subjects than in nonmetabolic syndrome subjects. ${ }^{17}$ Moreover, PON1 Q192R polymorphism has been consistently associated with CAD among subjects with type 2 diabetes, ${ }^{18-21}$ a condition with high oxidative stress.

We conducted a case-control study in Beijing, China, to investigate the association between $P O N 1$ Q192R polymorphism and the risk of $\mathrm{MI}$ and whether the association can be modified by DM and obesity.

\section{METHODS}

\section{Study population}

Study subjects were enrolled from 1996 to 1998 in Beijing, China. All subjects gave informed consent, and the study protocol was approved by the Institutional Review Board of the Health Science Center of Peking University and Harvard School of Public Health.

A total of $156 \mathrm{MI}$ cases with an age range of 32 to 72 years were enrolled from the Department of Cardiology, the Peking University First Affiliated Hospital. All the cases were admitted to the hospital and diagnosed with acute MI according to the criteria of World Health Organization (WHO). A total of 156 age- (within 5 years) and sex- matched controls were enrolled from the hospitalized noncardiac patients in the other departments of the same hospital, including Pulmonary Diseases, Digestive Diseases, General Surgery, Orthopedics, and Urology. All the controls had no history of CAD and showed normal findings on cardiac physical examination, electrocardiogram, and echocardiography. As there were 4 body mass index (BMI) data missing ( 2 in cases and 2 in controls), in the subsequent analysis we just focused on the 154 cases and 154 controls with full demographic information.

\section{Epidemiological and clinical data}

A standard questionnaire was administered by a trained interviewer to obtain information on each subject's history of physician-diagnosed diseases, including hypertension, hyperlipidemia, and diabetes mellitus, and environmental exposures, including cigarette smoking and alcohol consumption. Height and weight were measured by trained examiners after each subject removed shoes and outer wear; height was measured to the nearest $1 \mathrm{~mm}$ on a portable stadiometer, and weight was measured to the nearest $0.1 \mathrm{~kg}$ with the subject standing motionless on the scale. BMI was calculated as weight $(\mathrm{kg}) /$ height $\mathrm{t}^{2}\left(\mathrm{~m}^{2}\right)$. Obesity is defined as BMI $>27 \mathrm{~kg} / \mathrm{m}^{2}$ according to the suggested criteria of obesity for Asian populations. ${ }^{22}$ Cigarette smokers were defined as those who smoked at least one cigarette per day and had smoked more than 1 year. Ever smokers included both current smokers and former smokers who had quit smoking. Alcohol drinkers were defined as those who drank at least two times a week and had drunk for more than 1 year. Ever drinkers include current drinkers and former drinkers who had quit drinking. Hypertension was defined as systolic blood pressure $\geq 140 \mathrm{~mm} \mathrm{Hg}$ and/or diastolic blood pressure $\geq 90 \mathrm{~mm} \mathrm{Hg}$, or treatment with antihypertensive medication. Diabetes mellitus was defined as fasting blood glucose levels above $110 \mathrm{mg} / \mathrm{dL}$, or treatment with antidiabetic medication. Hyperlipidemia was defined as total cholesterol $(\mathrm{TCHO})>5.1 \mathrm{mmol} / \mathrm{L}$ and/or low-density lipoprotein (LDL) $>3.1 \mathrm{mmol} / \mathrm{L}$ or currently taking lipid lowing medications.

\section{Genotyping methods}

The genomic DNA was isolated from white blood cells by a previously described DNA extraction methods. ${ }^{23}$ PON1 Q192R genotype was determined by PCR amplification of genomic DNA followed by restriction-endonuclease digestion. The detailed method has been published elsewhere. ${ }^{7}$

\section{Statistical analysis}

Continuous variables for cases and controls were expressed as mean and standard error (SE) and were compared using Student's $t$ test. Categorical variables were presented as counts and percentages and were compared by chi-square test. The concordance of the genotype frequency distribution with the Hardy-Weinberg equilibrium was evaluated by a chi-square test. The association of PON1 Q192R polymorphism with the risk of MI was investigated sequentially. First, we investigated whether the Q192R Polymorphism is an independent risk factor of MI. This polymorphism has three possible genotypes: $\mathrm{QQ}, \mathrm{QR}$, and RR. A chi-square test was performed to compare the genotype distribution among the cases and controls. Then a logistic regression analysis was performed to estimate odds ratio (OR) and 95\% confidence interval (CI) of MI by comparing individuals taking different genotypes. The logistic regression analysis adjusted for age (as a continuous variable), sex, BMI (as a continuous variable), cigarette smoking (ever, never), alcohol consumption (ever, never), and history of physician-diagnosed hypertension (yes, no), diabetes mellitus (yes, no), and hyperlipidemia (yes, no). We evaluated 4 possible genetic models: Dominant $(\mathrm{QQ}=0, \mathrm{QR}=1$, and $\mathrm{RR}=1)$; recessive $(\mathrm{QQ}=0, \mathrm{QR}=0$, and $\mathrm{RR}=1)$; additive $(\mathrm{QQ}=0$, $\mathrm{QR}=1$, and $\mathrm{RR}=2$ ); and no restriction (no assumption made). We found that the risk of MI was similar between QR and RR genotype, but differed between QQ and QR genotype. Thus, our data suggested an additive or dominant role for the $R$ allele (or a recessive role for the Q allele). In the subsequent analysis of joint association of genotype and other risk factors of MI, we combined QR and RR genotypes together, and used QQ genotype as reference group.

We further investigated whether the association between PON1 Q192R polymorphism and MI can be modified by the conditions of DM and obesity while adjusting for other important covariates including hypertension, hyperlipidemia, and cigarette smoking. We first examined the joint association of PON1 Q192R genotype and each of the two conditions with $\mathrm{MI}$, in which the subjects were divided into four groups according to the genotype (QQ, QR/RR) and the condition: $\mathrm{DM}$ (yes, no), or obesity (BMI $<27, \mathrm{BMI} \geq 27$ ). Then, we examined the joint association of genotype and both of the two conditions with MI. We compared six groups defined by geno- 
type (QQ, QR/RR) and presence of the two conditions (neither obesity nor DM, either obesity or DM, both obesity and DM). We also tested potential interaction between genotype and DM and between genotype and obesity using a multivariate logistic regression model by including a product term of PON1 Q192R polymorphism $\times$ DM and the PON1 Q192R polymorphism $\times$ obesity. All the statistical analyses were performed using SAS statistical software, version 6.12. A value of $P<0.05$ was considered to be statistically significant on two-sided test.

\section{RESULTS}

The demographic and clinical characteristics of cases and controls are summarized in Table 1. As compared to control

Table 1

Characteristics of the cases and the controls, Beijing, China

\begin{tabular}{lcc}
\hline Variable & Controls $(n=154)$ & Cases $(n=154)$ \\
\hline Age $($ years $)$ & $56.2 \pm 9.3$ & $56.3 \pm 9.2$ \\
BMI $\left(\mathrm{Kg} / \mathrm{m}^{2}\right)$ & $23.9 \pm 3.1$ & $25.6 \pm 3.1 \dagger$ \\
Sex & & \\
$\quad$ Male & $124(80.5)$ & $123(79.9)$ \\
$\quad$ Female & $30(19.5)$ & $31(20.1)$ \\
History of hypertension & & \\
No & $119(77.3)$ & $81(52.6) \dagger$ \\
Yes & $35(22.7)$ & $73(47.4)$
\end{tabular}

History of Diabetes Mellitus

$\begin{array}{ccc}\text { No } & 145(94.2) & 114(74.0) \dagger \\ \text { Yes } & 9(5.8) & 40(26.0)\end{array}$

History of Hyperlipidemia

$\begin{array}{ccc}\text { No } & 147(95.5) & 107(69.5) \dagger \\ \text { Yes } & 7(4.5) & 47(30.5)\end{array}$

Obesity

$\begin{array}{lrc}\text { No } & 132(85.7) & 101(65.6) \dagger \\ \text { Yes } & 22(14.3) & 53(34.4)\end{array}$

Smoking status

$\begin{array}{lrr}\text { Never } & 47(30.9) & 38(25.3) \\ \text { Ever } & 105(69.1) & 112(74.7) \\ \text { Alcohol drinking } & & \\ \text { Never } & 103(66.9) & 108(70.1) \\ \text { Ever } & 51(33.1) & 46(29.9)\end{array}$

PON1 Q192R genotype

\begin{tabular}{lll} 
QQ & $31(20.1)$ & $27(17.5)$ \\
QR & $73(47.4)$ & $66(42.9)$ \\
RR & $50(32.5)$ & $61(39.6)$ \\
\hline
\end{tabular}

Continuous variables are expressed as mean \pm standard error and categorical variables are expressed as counts and percentage; obesity was defined as BMI $\geq$ $27 ;{ }^{\star} P<0.05, \uparrow P<0.01$. group, case group had a significantly higher level of BMI and higher proportion of history of physician diagnosed hypertension, DM, hyperlipidemia, and obesity. The respective frequencies of Q (Gln) and R (Arg) alleles for the PON1 Q192R polymorphism were 0.44 and 0.56 among controls and 0.39 and 0.61 among cases. Genotype frequencies were concordant with Hardy-Weinberg equilibrium among both cases $\left(\chi_{1}^{2}=\right.$ $1.38, P=0.24)$ and controls $\left(\chi_{1}^{2}=0.23, P=0.63\right)$. It is noted that the frequency of $\mathrm{R}$ allele is higher in the cases than in the controls; however, the difference was not statistically significant.

Table 2 presents genotype frequency among cases and controls, and adjusted association of $P O N 1$ Q192R polymorphism with the risk of MI for the total sample and stratified by obese and DM status. As compared to the subjects with QQ genotype (the reference group), the adjusted OR for subjects with QR genotype, RR genotype, and combined $\mathrm{QR}$ and RR genotypes (QR/RR) were 1.3 (95\% CI: 0.6-2.6), 1.4 (95\%CI: 0.7-3.0), and 1.3 (95\% CI: 0.7-2.6), respectively. It is noted that OR differs in obesity and DM strata, with obese and DM subjects had greater OR than nonobese or non-DM subjects.

Table 3 presents the joint association of PON1 Q192R genotype and obesity with the risk of MI. As compared to the nonobese subjects with QQ genotype (the reference group), the obese subjects with QR/RR genotype had the highest risk of MI: OR $=2.9$ (95\%CI: $1.2-7.1, P=0.02)$. A test of interaction between the genotype and obesity by including their product term in the logistic regression model was not statistically significant $(\mathrm{OR}=1.4,95 \% \mathrm{CI}$ : 0.3-7.5, $P=0.71$, data available upon request). Similarly, Table 4 presents the joint association of PON1 Q192R genotype and DM with the risk of MI. As compared to the non-DM subjects with QQ genotype (the reference group), the DM subjects with $\mathrm{QR} / \mathrm{RR}$ genotype had the highest risk of MI: OR $=8.4$ (95\%CI: $2.5-28.0, P<0.01$ ). A test of interaction between the genotype and DM by including their product term in the logistic regression model was suggestive but not statistically significant $(\mathrm{OR}=3.5,95 \%$ CI: $0.6-$ 21.4. $P=0.22$, data available upon request). Based on the results from Tables 3 and 4 , the modifying effect of diabetes appears to be greater than obesity.

Table 5 presents the joint association of PON1 Q192R genotype, DM and obesity with the risk of MI. As compared to subjects without DM and obesity and with QQ genotypes (reference group), there is a trend of increased risk of MI among subjects with the presence of either DM or obesity $(\mathrm{OR}=1.9$, 95\% CI: $0.5-7.3, P=0.34)$ and both $(\mathrm{OR}=4.5,95 \% \mathrm{CI}$ : $0.4-55.2, P=0.24)$. On the other hand, QR/RR genotype alone in the absence of DM and obesity was not associated with increased risk of $\mathrm{MI}(\mathrm{OR}=1.1,95 \% \mathrm{CI}$ : $0.5-2.3, P=0.89)$. In the presence of either DM or obesity, the risk of MI for subjects with $\mathrm{QR} / \mathrm{RR}$ genotype was significantly increased $(\mathrm{OR}=3.6$, 95\% CI: 1.5-8.7, $P<0.01)$. The highest risk of MI was found among subjects with $\mathrm{QR} / \mathrm{RR}$ genotype and with both $\mathrm{DM}$ and obesity (OR $=13.6,95 \%$ CI: $1.5-124.8, P=0.02)$. 
Table 2

Association of PON1 Q192R polymorphism with the risk of MI in all the subjects and in subjects stratified by obesity and diabetes

\begin{tabular}{|c|c|c|c|c|c|}
\hline \multirow[b]{2}{*}{ Genotype } & \multicolumn{2}{|c|}{ No. of Subjects (\%) } & \multicolumn{2}{|c|}{ Adjusted $^{a}$} & \multirow[b]{2}{*}{$P$} \\
\hline & Controls & Cases & OR & $95 \% \mathrm{CI}$ & \\
\hline \multicolumn{6}{|l|}{ All } \\
\hline QQ & $31(20.1)$ & $27(17.5)$ & 1.0 & & \\
\hline QR & $73(47.4)$ & $66(42.9)$ & 1.3 & $0.6-2.6$ & 0.50 \\
\hline $\mathrm{RR}$ & $50(32.5)$ & $61(39.6)$ & 1.4 & $0.7-3.0$ & 0.35 \\
\hline QR/RR & $124(80.5)$ & $129(83.8)$ & 1.3 & $0.7-2.6$ & 0.39 \\
\hline \multicolumn{6}{|l|}{ Obese } \\
\hline QQ & $4(18.2)$ & $9(17.0)$ & 1.0 & & \\
\hline $\mathrm{QR} / \mathrm{RR}$ & $18(81.8)$ & $44(83.0)$ & 1.4 & $0.3-5.7$ & 0.65 \\
\hline \multicolumn{6}{|l|}{ Nonobese } \\
\hline QQ & $27(20.5)$ & $18(17.8)$ & 1.0 & & \\
\hline $\mathrm{QR} / \mathrm{RR}$ & $105(79.5)$ & $83(82.2)$ & 1.1 & $0.6-2.4$ & 0.72 \\
\hline \multicolumn{6}{|l|}{$\mathrm{DM}$} \\
\hline QQ & $4(44.4)$ & $7(17.5)$ & 1.0 & & \\
\hline QR/RR & $5(55.6)$ & $33(82.5)$ & 5.7 & $0.8-42.5$ & 0.09 \\
\hline \multicolumn{6}{|l|}{ Non-DM } \\
\hline QQ & $27(18.6)$ & $20(17.5)$ & 1.0 & & \\
\hline QR/RR & $118(81.4)$ & $94(82.5)$ & 1.2 & $0.6-2.4$ & 0.63 \\
\hline
\end{tabular}

${ }^{a}$ Adjusted OR was calculated by adjusting age, sex, history of physician diagnosed hypertension, and hyperlipidemia, cigarette smoking, and alcohol consumption.

Table 3

Joint association of PON1 Q192R polymorphism and obesity with the risk of MI

\begin{tabular}{|c|c|c|c|c|c|c|}
\hline \multirow[b]{2}{*}{ Genotype } & \multirow[b]{2}{*}{ Obesity } & \multicolumn{2}{|c|}{ No. of Subjects (\%) } & \multicolumn{2}{|c|}{ Adjusted $^{a}$} & \multirow[b]{2}{*}{$P$} \\
\hline & & Controls & Cases & OR & $95 \%$ CI & \\
\hline QQ & No & $27(17.5)$ & $18(11.7)$ & 1.0 & & \\
\hline QQ & Yes & $4(2.6)$ & $9(5.8)$ & 1.6 & $0.3-7.9$ & 0.53 \\
\hline QR/RR & No & $105(68.2)$ & $83(53.9)$ & 1.3 & $0.6-2.6$ & 0.53 \\
\hline $\mathrm{QR} / \mathrm{RR}$ & Yes & $18(11.7)$ & $44(28.6)$ & 2.9 & $1.2-7.1$ & 0.02 \\
\hline
\end{tabular}

${ }^{a}$ Adjusted OR was calculated by adjusting age, sex, history of physician diagnosed hypertension, diabetes, and hyperlipidemia, cigarette smoking, and alcohol consumption.

\section{DISCUSSION}

PON1 has received considerable attention in the last decade because of its potential role in antioxidation of LDL. So far at least three polymorphisms have been investigated in relation to CAD. Among them, only the polymorphism of Q192R was found to have a weak association with CAD in a recent metaanalysis. ${ }^{6}$ This polymorphism is caused by an amino acid substitution of Gln Q by R at position 192. Its allele frequencies varied among populations. ${ }^{24}$ The $\mathrm{Q}$ allele is more frequent than R alleles in Caucasians and in Indians. But in Japanese and Chinese, the $\mathrm{R}$ allele is more frequent than $\mathrm{Q}$ allele. Our results of the allele frequencies are consistent with Chinese living in Singapore ${ }^{8}$ and Taiwan..$^{15}$ It has been shown that the R allele determines a higher activity of paraoxonase, ${ }^{25}$ but in most studies, it was found to relate to a higher risk of CAD. This may reflect the fact that all the current assays for measurement of enzymatic activity are not indicative of the protective role of PON1 in preventing LDL oxidation. It has been shown that the PON1 R allozyme is less efficient at retarding the oxidation of LDL than is the Q allozyme because of the decreased hydrolysis of lipid peroxides by the $\mathrm{R}$ allozyme. ${ }^{26} \mathrm{~A}$ recent study showed that subjects with 192RR genotype were prone to have coronary spasm, ${ }^{27}$ which reflects the endothelium dysfunction related to oxidative damage, providing further supports that the $\mathrm{R}$ allele could increase a subject's susceptibility to CAD. However, studies so far have yielded inconsistent findings on the relationship between the PON1 Q192R polymorphism and $\mathrm{CAD}$. Although these inconsistent findings may simply reflect 
Table 4

Joint association of PON1 Q192R polymorphism and diabetes mellitus (DM) with the risk of MI

\begin{tabular}{|c|c|c|c|c|c|c|}
\hline \multirow[b]{2}{*}{ Genotype } & \multirow[b]{2}{*}{$\mathrm{DM}$} & \multicolumn{2}{|c|}{ No. of Subjects (\%) } & \multicolumn{2}{|c|}{ Adjusted $^{a}$} & \multirow[b]{2}{*}{$P$} \\
\hline & & Controls & Cases & OR & $95 \%$ CI & \\
\hline QQ & No & $27(17.5)$ & $20(13.0)$ & 1.0 & & \\
\hline QQ & Yes & $4(2.6)$ & $7(4.6)$ & 2.3 & $0.5-10.0$ & 0.27 \\
\hline $\mathrm{QR} / \mathrm{RR}$ & No & $118(76.6)$ & $94(61.0)$ & 1.1 & $0.5-2.3$ & 0.76 \\
\hline QR/RR & Yes & $5(3.2)$ & $33(21.4)$ & 8.4 & $2.5-28.0$ & $<0.01$ \\
\hline
\end{tabular}

${ }^{a}$ Adjusted OR was calculated by adjusting age, sex, BMI, history of physician diagnosed hypertension and hyperlipidemia, cigarette smoking, and alcohol consumption.

Table 5

Joint association of PON1 Q192R polymorphism, obesity, and DM with the risk of MI

\begin{tabular}{|c|c|c|c|c|c|c|}
\hline \multirow[b]{2}{*}{ Genotype } & \multirow[b]{2}{*}{ DM/Obesity status } & \multicolumn{2}{|c|}{ No. of Subjects (\%) } & \multicolumn{2}{|c|}{ Adjusted $^{a}$} & \multirow[b]{2}{*}{$P$} \\
\hline & & Controls & Cases & OR & $95 \%$ CI & \\
\hline QQ & Neither & $24(15.6)$ & $15(9.7)$ & 1.0 & & \\
\hline QQ & Either & $6(3.9)$ & $8(5.2)$ & 1.9 & $0.5-7.3$ & 0.34 \\
\hline QQ & Both & $1(0.6)$ & $4(2.6)$ & 4.5 & $0.4-55.2$ & 0.24 \\
\hline $\mathrm{QR} / \mathrm{RR}$ & Neither & $101(65.6)$ & $62(40.3)$ & 1.1 & $0.5-2.3$ & 0.89 \\
\hline $\mathrm{QR} / \mathrm{RR}$ & Either & $21(13.6)$ & $53(34.4)$ & 3.6 & $1.5-8.7$ & $<0.01$ \\
\hline $\mathrm{QR} / \mathrm{RR}$ & Both & $1(0.7)$ & $12(7.8)$ & 13.6 & $1.5-124.8$ & 0.02 \\
\hline
\end{tabular}

DM/Obesity Status: Neither: the subjects did not have DM nor obesity; Either: the subjects had either DM or obesity; Both: the subjects had both DM and obesity. Obesity is defined as BMI $\geq 27$.

${ }^{a}$ Adjusted OR was calculated by adjusting age, sex, history of physician diagnosed hypertension and hyperlipidemia, cigarette smoking, and alcohol consumption.

the imponderables of genetic association studies, ${ }^{28}$ another possibility is that, within each study population, individuals carrying the $\mathrm{R}$ allele could be at increased risk for CAD only when they are exposed to certain conditions. As PON1 plays a role in antioxidation, we hypothesize that $P O N 1$ Q192R polymorphism would influence the risk of CAD only in the presence of elevated oxidative stress, for example, among individuals with DM and obesity, two components of metabolic syndrome with high likelihood of insulin resistance. In diabetic subjects, chronic hyperglycemia could cause considerable modification of lipoprotein structure and function due to nonenzymatic glycosylation of amino acid residues and glycosylated LDL is more readily oxidized. ${ }^{29-31}$ Insulin resistance could lead to smaller and dense LDL particles, which are more easily oxidized in vitro. ${ }^{32,33}$ Two studies demonstrated that insulin resistance is significantly associated with LDL oxidized state in vivo. ${ }^{34,35}$ Animal studies as well as in vitro human studies also provided the direct evidence that the oxidative stress increases in obese subjects. ${ }^{36-38}$

Our data demonstrated that the PON1 Q192R genotype alone in the absence of DM and obesity was not associated with increased risk of MI. In the presence of either DM or obesity, the risk of MI for subjects with QR/RR genotype was considerably increased. The highest risk of MI was found among subjects with QR/RR genotype and with both DM and obesity. Our findings indicate that high oxidative stress may play an important role in modifying the association between the PON1
Q192R polymorphism and MI. Our findings underscore the importance to take both DM and obesity into consideration in studying the association between the PON1 Q192R genotype and the risk of CAD or MI.

Our study represents the very first step in understanding the complex interplay of genetic factors and clinical characteristics in determining individual susceptibility to common disorders such as MI. Results reported in this study are hypothesis-generating only because of the small sample size and single polymorphism that are studied as well as the issue of multiple comparisons. Our findings need to be replicated in other independent populations. If validated, such information could help explain the inconsistent findings on the association between PON1 Q192R and MI and may help clinicians identify individuals at high-risk for MI.

\section{ACKNOWLEDGMENTS}

This study is supported in part by an educational grant of Peking University Health Science Center. We gratefully acknowledge the assistance and cooperation of the faculty and staff of the Peking University Health Science Center and the Center for reproductive Health and Eco-Genetics.

\section{References}

1. World Health Organization. The World Health Report 1999: Making a difference. Geneva: WHO. 
2. Wu Z, Yao C, Zhao D, Wu G, Wang W, Liu J, Zeng Z, Wu Y. Sino-MONICA project: a collaborative study on trends and determinants in cardiovascular diseases in China, part I: Morbidity and mortality monitoring. Circulation 2001;103:462-468.

3. Marenberg ME, Risch N, Berkman LF, Floderus B, Faire UD. Genetic susceptibility to death from coronary heart disease in a study of twins. N Engl J Med 1994;330: 1041-1046.

4. Mackness MI, Arrol S, Abbott CA, Durrington PN. Is paraoxonase related to atherosclerosis? Chem Biol Interact 1993;87:161-171.

5. Mackness MI, Arrol S, Durrington PN. Paraoxonase prevents accumulation of lipoperoxides in low density lipoprotein. FEBS Lett 1991;286:152-154.

6. Wheeler JG, Keavney BD, Watkins H, Collins R, Danesh J. Four paraoxonase gene polymorphisms in 11212 cases of coronary heart disease and 12786 controls: metaanalysis of 43 studies. Lancet 2004;363:689-695.

7. Serrato M, Marian AJ. A variant of human paraoxonase/arylesterase (HUMPONA) gene is a risk factor for coronary artery disease. J Clin Invest 1995;96:3005-3008.

8. Sanghera DK, Saha N, Aston CE, Kamboh MI. Genetic polymorphism of paraoxonase and the risk of coronary heart disease. Arterioscler Thromb Vasc Biol 1997;17: 1067-1073.

9. Sanghera DK, Aston CE, Saha N, Kamboh MI. DNA polymorphisms in two paraoxonase genes (PON1 and PON2) are associated with the risk of coronary heart disease. Am J Hum Genet 1998;62:36-44.

10. Imai $Y$, Morita H, Kurihara H, Sugiyama T, Kato N, Ebihara A et al. Evidence for association between paraoxonase gene polymorphisms and atherosclerotic diseases. Atherosclerosis 2000;149:435-442.

11. Herrmann SM, Blanc H, Poirier O, Arveiler D, Luc G, Evans A et al. The Gln/Arg polymorphism of human paraoxonase (PON 192) is not related to myocardial infarction in the ECTIM Study. Atherosclerosis 1996;126:299-303.

12. Ombres D, Pannitteri G, Montali A, Candeloro A, Seccareccia F, Campagna F et al. The Gln-Arg192 polymorphism of human paraoxonase gene is not associated with coronary artery disease in Italian patients. Aterioscler Thromb Vasc Biol 1998;18: 1611-1616.

13. Antikainen M, Murtomaki S, Syvanne M, Pahlman R, Tahvanaien E, Jauhiainen M et al. The Gln-Arg191 polymorphism of the human paraoxonase gene (HUMPONA) is not associated with the risk of coronary artery disease in Finns. J Clin Invest 1996;98:883-885.

14. Hong SH, Song J, Min WK, Kim JQ. Genetic variations of the paraoxonase gene in patients with coronary artery disease. Clin Biochem 2001;34:475-481.

15. Ko YL, Ko YS, Wang SM, Hsu LA, Chang CJ, Chu PH et al. The Gln-Arg 191 polymorphism of the human paraoxonase gene is not associated with the risk of coronary artery disease among Chinese in Taiwan. Atherosclerosis 1998;141:259264

16. Martinelli N, Girelli D, Olivieri O, Stranieri C, Trabetti E, Pizzolo F et al. Interaction between smoking and PON2 Ser311Cys polymorphism as a determinant of the risk of myocardial infarction. Eur J Clin Invest 2004;34:14-20.

17. Senti M, Tomas M, Fito M, Weinbrenner T, Covas MI, Sala J et al. Antioxidan paraoxonase 1 activity in the metabolic syndrome. J Clin Endocrinol Metab. 2003; 88:5422-5426.

18. Ruiz J, Blanche H, James RW, Garin MC, Vaisse C, Charpentier G et al. Gln-Arg192 polymorphism of paraoxonase and coronary heart disease in type 2 diabetes. Lancet 1995;346:869-872.

19. Pfohl M, Koch M, Enderle MD, Kuhn R, Fullhase J, Karsch KR et al. Paraoxonase $192 \mathrm{Gln} /$ Arg gene polymorphism, coronary artery disease, and myocardial infarction in type 2 diabetes. Diabetes 1999;48:623-627.
20. Odawara M, Tachi Y, Yamashita K. Paraoxonase polymorphism (Gln192-Arg) is associated with coronary heart disease in Japanese noninsulin-dependent diabetes mellitus. J Clin Endocrinol Metab 1997;82:2257-2260.

21. Heijmans BT, Westendorp RG, Lagaay AM, Knook DL, Kluft C, Slagboom PE Common paraoxonase gene variants, mortality risk and fatal cardiovascular events in elderly subjects. Atherosclerosis 2000;149:91-97.

22. Deurenberg-Yap M, Schmidt G, van Staveren WA, Deurenberg P. The paradox of low body mass index and high body fat percentage among Chinese, Malays and Indians in Singapore. Int J Obes Relat Metab Disord 2000;24:1011-1017.

23. Buffone GJ, Darlington GJ. Isolation of DNA from biological specimens without extraction with phenol. Clin Chem 1985;31:164-165.

24. Scacchi R, Corbo RM, Rickards O, De Stefano GF. New data on the world distribution of paraoxonase (PON1 Gln192-Arg) gene frequencies. Hum Biol 2003;75:365373

25. Adkins S, Karen NG, Mody M, La Du BN. Molecular basis for the polymorphic forms of human serum paraoxonase /arylesterase: Glutamine or Arginine at position 191, for the respective A or B allozymes. Am J Hum Genet 1993;52:598-608.

26. Mackness B, Mackness MI, Arrol S, Turkie W, Durrington PN. Effects of the human serum paraoxonase 55 and 192 genetic polymorphisms on the protection by high density lipoprotein against low density lipoprotein oxidative modification. FEBS lett 1998;423:57-60.

27. Ito T, Yasue H, Yoshimura M, Nakamura S, Nakayama M, Shimasaki Y, Harada E Mizuno Y, Kawano H, Ogawa H. Paraoxonase gene Q192R (Q192R) polymorphism is associated with coronary artery spasm. Hum Genet 2002;110:89-94.

28. Lander ES, Schork NJ. Genetic dissections of complex traits. Science 1994;265:20372048 .

29. Reaven GM, Chen Y-DI, Jeppesen J, Maheux P, Krauss RM. Insulin resistance and hyperinsulinemia in individuals with small, dense, low density lipoprotein particles. J Clin Invest 1993;92:141-146.

30. De Graaf J, Hak-Lemmers HL, Hectors MP, Demacker PN, Hendriks JC, Stalenhoe AF. Enhanced susceptibility to in vitro oxidation of the dense low density lipoprotein subfraction in healthy subjects. Arterioscler Thromb 1991;11:298 -306.

31. Carantoni M, Abbasi F, Warmerdam F, Klebanov M, Wang PW, Chen YD et al. Relationship between insulin resistance and partially oxidized LDL particles in healthy, nondiabetic volunteers. Arterioscler Thromb Vasc Biol 1998;18:762-767.

32. Chen NG, Azhar S, Abbasi F, Carantoni M, Reaven GM. The relationship between plasma glucose and insulin responses to oral glucose, LDL oxidation, and soluble intercellular adhesion molecule-1 in healthy volunteers. Atherosclerosis 2000;152: 203-208.

33. Chisolm GM, Irwin KC, Penn MS. Lipoprotein oxidation and lipoprotein-induced cell injury in diabetes. Diabetes 1992;41(suppl 2):61-66.

34. Hunt JV, Smith CC, Wolff SP. Autoxidative glycosylation and possible involvement of peroxides and free radicals in LDL modification by glucose. Diabetes 1990;39: 1420-1424.

35. Bucala R, Makita Z, Koschinsky T, Cerami A, Vlassara H. Lipid advanced glycosylation: pathway for lipid oxidation in vivo. Proc Natl Acad Sci U S A 1993;90:6434-6438.

36. Nakao C, Ookawara T, Sato Y. Kizaki T, Imazeki N, Matsubara O et al. Extracellular superoxide dismutase in tissues from obese mice. Free Radic Res 2000;33:229-241.

37. Dobrian AD, Davies MJ, Schriver SD, Lauterio TJ, Prewitt RL. Oxidative stress in a rat model of obesity induced hypertension. Hypertension 2001;37:554-560.

38. Van Gaal LF, Vertommen J, De Leeuw IH. The in vitro oxidizability of lipoprotein particles in obese and non-obese subjects. Atherosclerosis 1998;137(suppl): S39-S44. 